\title{
Implicações da mastectomia na autoestima da mulher
}

\author{
Complications of mastectomy in homan's self-steen
}

Complicaciones de la mastectomía en el autoestima de mujeres

\begin{abstract}
Marcela Savegnago dos Santos ${ }^{1 *}$, Daiane de Francisco Lira Freitas ${ }^{1}$, Josimeire Souza de Oliveira Andrade ${ }^{1}$, Francisco Mateus Lima da Silva ${ }^{1}$.
\end{abstract}

\section{RESUMO}

Objetivo: Descrever os aspectos implicadores da mastectomia na autoestima das mulheres que participam da casa de apoio Irmã Rosa Gambelli. Metodologia: Trata-se de um trabalho descritivo, exploratório de abordagem qualitativa. A população desta pesquisa foi constituída por 10 mulheres com faixa etária entre 30 e 69 anos e que foram submetidas à mastectomia e que estão acomodadas na Casa de Apoio Irmã Gambelli, localizada no município de Porto Velho, Rondônia. Foi realizada uma entrevista de quatorze (14) perguntas abertas com roteiro semiestruturado. A pesquisa foi aprovada pelo Comitê de Ética em Pesquisa (CEP). Resultados: Identificou-se que as mulheres pós-mastectomia apresentavam uma baixa autoestima pela falta da mama e por motivos de negação de sua autoaceitação corporal, além de sofrerem percas no convívio social e amoroso. Conclusão: A partir da análise de conteúdo, nos permitiu concluir que os resultados evidenciaram que: as mulheres com baixa autoestima após a mastectomia se mostraram afetadas com este procedimento envolvendo os aspectos físico e emocional em sua identidade feminina, além de nos apresentar suas experiências em um momento tão delicado, despertando a empatia, frente aos obstáculos por elas vivenciados.

Palavras chave: Câncer, Mulher, Autoestima, Mastectomia.

\section{ABSTRACT}

Objective: To describe the implication aspects of mastectomy in the self-esteem of women who participate in the support house sister Rosa Gambelli. Methodology: This is a descriptive, exploratory work with a qualitative approach. The population of this research consisted of 10 women aged between 30 and 69 years who underwent mastectomy and who are accommodated in the Support House Sister Gambelli, located in the municipality of Porto Velho, Rondônia. An interview was conducted of fourteen (14) open questions with semistructured script. The research was approved by the Research Ethics Committee (CEP). Results: It was identified that post-mastectomy women had low self-esteem due to lack of breast and for reasons of denial of their corporal self-acceptance, in addition to suffering losses in social and loving life. Conclusion: Based on the content analysis, we concluded that the results showed that: women with low self-esteem after mastectomy were affected by this procedure involving the physical and emotional aspects of their female identity, as well as presenting their experiences in a moment so delicate, arousing empathy, in the face of the obstacles they experienced.

Key words: Cancer, Woman, Self esteem, Mastectomy.

\section{RESUMEN}

Objetivo: Describir los aspectos implicados de la mastectomía en la autoestima de mujeres que participan en la casa de apoyo hermana Rosa Gambelli. Metodología: Se trata de un trabajo descriptivo, exploratorio, con abordaje cualitativo. La población de esta investigación fue compuesta por 10 mujeres con edad entre 30 y 69 años sometidas a la mastectomía y que están alojadas en la Casa de Apoyo Sister Gambelli, ubicada en el municipio de Porto Velho, Rondônia. Se realizó una entrevista de catorce (14) preguntas abiertas con guión semiestructurado. La encuesta fue aprobada por el Comité de Ética en Investigación (CEP). Resultados: Se

1União das Escolas Superiores de Rondônia (UNIRON), Porto Velho - RO. *E-mail: marcelasavegnago@gmail.com

SUBMETIDO EM: 6/2019

ACEITO EM: 6/2019

PUBLICADO EM: 7/2019

REAS | Vol. Sup. 29 | e1124 | DOI: https://doi.org/10.25248/reas.e1124.2019 
identificó que las mujeres post-mastectomía presentaron baja autoestima por falta de mama y por motivos de negación de su auto-aceptación corporal, además de sufrir pérdidas en la vida social y amorosa. Conclusión: Con base en el análisis de contenido, concluimos que los resultados mostraron que las mujeres con baja autoestima después de la mastectomía fueron afectadas por este procedimiento envolviendo los aspectos físicos y emocionales de su identidad femenina, así como presentando sus experiencias en un momento tan empatia delicada, despertando, frente a los obstáculos que ellos experimentaron.

Palabras clave: Cáncer, Mujer, Autoestima, Mastectomía.

\section{INTRODUÇÃO}

O câncer de mama é o segundo mais frequente no mundo e atinge, principalmente, as mulheres, apesar de também acometer os homens, no entanto, em uma proporção bem menor, atinge um homem para cada mil mulheres, o que representa menos de $1 \%$ entre todos os cânceres nos homens (SALOMON MFB et al., 2015). Estima-se que no Brasil o câncer de mama seja diagnosticado em $22 \%$ de todos os novos casos de câncer nas mulheres, tornando-se um índice significativo para as políticas públicas de saúde (NASCIMENTO KTS et al., 2015).

O câncer de mama pode ser tratado clínico ou cirurgicamente. O tratamento clínico baseia-se na utilização de medicamentos quimioterápicos, hormonioterápicos e na radioterapia. A escolha de cada tratamento ocorrerá de forma individual, conforme cada caso apresentado. Já o tratamento cirúrgico inclui a tumorectomia, quadrantectomia ou a mastectomia. A tumorectomia é a retirada apenas do tumor e a quadrantectomia é a retira parcial da mama, enquanto que a mastectomia é a retirada total da mama (PRATES ACL et al., 2014).

Na mastectomia simples, são retiradas somente as glândulas mamárias e a aponeurose no musculo peitoral maior, sendo este tipo mais indicado para casos em que o carcinoma se encontra bem localizado e o diagnóstico do câncer ocorreu precocemente. Já a mastectomia preventiva ocorre quando a mulher opta por retirar a mama como meio de prevenção ao câncer, indicada em casos em que a mulher já foi acometida por um câncer em uma das mamas ou para aquelas que possuem um risco elevado para o desenvolvimento da doença. No caso da mastectomia radical, o ato cirúrgico consiste na retirada total da glândula mamária do músculo peitoral e dos linfonodos axilares (GODOY MK et al., 2016).

A escolha pelo tratamento cirúrgico radical possui repercussões emocionais e funcionais para a vida, uma vez que a mama tem significados profundos para a mulher, ligados à sexualidade, feminilidade e maternidade. Desta forma, o que pode parecer simples e de tratamento imediato para uma doença tão agressiva que é o câncer de mama, passa a ser um pesadelo na vida das mulheres mastectomizadas, uma vez que as mamas apresentam profundos significados em suas vidas, relacionados à harmonização e erotização do corpo feminino (COSTA et al., 2015).

Pacientes oncológicos apresentam um preocupante quadro de baixa autoestima diante do estigma de morte que a doença carrega e em se tratando de pacientes que precisam passar por procedimentos de remoção cirúrgica de alguma parte visível como as mamas, os pés, dentre outros, sua autoestima é ainda mais abalada e aprofundada diante da mudança da estrutura corporal do paciente, sendo inclusive motivação para a tentativa de suicídio, a depressão profunda, a mudanças bruscas de comportamento e até mesmo o abandono do tratamento (CASTRO EK et al., 2015).

A mastectomia é um procedimento que causa um impacto profundo na saúde mental da mulher devido a mama também ser um órgão sexual e, ao mesmo tempo, integrando a imagem da constituição de ser mulher, desta forma, comprometendo a imagem corporal de si mesma e para os demais, comprometendo, automaticamente, sua autoestima (NOAL SJ, BERGAMASCHI, 2017).

Diante disto, tomamos, então, como objetivo, descrever os aspectos implicadores da mastectomia na autoestima das mulheres que participam da casa de apoio irmã rosa Gambelli no município de Porto Velho RO. 


\section{MÉTODOS}

Trata-se de uma pesquisa descritiva e exploratória com abordagem qualitativa e que visa conhecer as implicações da mastectomia na autoestima das mulheres de uma casa de apoio. A população desta pesquisa foi constituída por 10 mulheres com faixa etária entre 30 e 69 anos que foram submetidas à mastectomia e que estão acomodadas na Casa de Apoio Irmã Gambelli em Porto Velho, Rondônia.

O estudo foi executado em 4 etapas, sendo a primeira realizada pesquisas bibliográficas na base de dados do SCIELO, LILACS e MEDLINE. A segunda etapa sendo busca por grupos em casas de apoio às mulheres com diagnóstico de câncer. A terceira etapa baseou-se na aplicação da entrevista com roteiro semiestruturado de 14 perguntas abertas com as mulheres incluídas na amostra, tendo o áudio gravado através de um gravador de voz para posterior transcrição das respostas e, por fim, a quarta etapa, onde foram realizadas as transcrições dos áudios na íntegra detalhando os pontos chaves e elencando os tópicos a serem discutidos e confrontados com a literatura.

A pesquisa iniciou-se após a aprovação do Comitê de Ética e Pesquisa (CEP) com o número de CAAE: 05084818.5.0000.8028 e número do Parecer: 3.132.265. Foram respeitadas as disposições contidas na Resolução de № 466/2012 do Conselho Nacional de Saúde (CNS) que trata das pesquisas com seres humanos.

\section{RESULTADOS E DISCUSSÃO}

Com base nesta investigação, identificamos que as mulheres pós mastectomia apresentavam uma baixa autoestima pela falta da mama e por motivos de negação de sua autoaceitação corporal, além de sofrerem percas no convívio social e amoroso. A maioria das mulheres entrevistadas mencionaram casos de câncer na família. Praticamente, todas relataram terem sido etilistas por muitos anos e algumas já consumiram bebidas álcoolicas socialmente.

Os dados coletados serviram para subsidiar a abordagem acerca de como as mulheres enfrentaram a remoção da mama, além de nos possibilitar analisar, à luz da literatura, as implicações geradas pela falta da mama, um órgão majoritariamente feminino, sexual e maternal que, ao mesmo tempo, repercute de forma negativa em sua autoestima, quer seja relacionado a sua autoimagem, quer seja ou no autoconceito de ser uma mulher completa.

Para Souza NHA, et al., (2017), o câncer de mama é a segunda neoplasia mais presente no mundo entre as mulheres. Estima-se que os casos aumentem em 50\% até o ano de 2020. Apesar de somente as mulheres com idade superior a 40 serem o público alvo para o rastreio do câncer de mama, a incidência desta doença, em mulheres jovens, tem aumentado consideravelmente. Devido ao diagnóstico tardio que ocorre, na maioria dos casos, as taxas de mortalidade ainda continuam elevadas.

\section{Implicações na autoestima da mulher}

A autoestima representa um importante complemento para o quadro de saúde mental e saúde biológica do ser humano. A forma como a pessoa se percebe, sente e se comporta diante da sua própria imagem, apresenta, de forma reflexa, a maneira com que ela vai interagir com o meio e, consequentemente, ela vai enfrentar os problemas cotidianos da vida (GOMES NS et al., 2015).

A retirada da mama repercute diretamente no visual da mulher, o que traz para ela uma sensação de perda, seguida da baixa autoestima, o que a leva refletir a respeito de sua autopercepção, modificando, assim, a visão de si mesma, o que afeta a aceitação de seu próprio corpo (AMBRÓSIO DCM e SANTOS MA, 2015).

A respeito disto, veremos algumas falas da entrevistada [A] que nos mostra exatamente isto, a dificuldade em enfrentar a situação durante o diagnóstico e após a mastectomia:

"Eu fiquei assim muito [...] como se eu tivesse tipo uma depressão, querendo ficar agressiva, pensando que aquilo ali ia ser o fim da minha vida."

"[...] agora tenho dificuldades de me olhar no espelho." 
Lago EA, et al., (2015) afirmam que depois do diagnóstico de câncer de mama, várias mulheres experimentam momentos de aflição, dor e preocupação por ser uma doença estigmatizada no meio social. No tratamento, elas vivenciam perdas físicas, econômicas, depressão, auto percepção de imagem prejudicada, baixa autoestima, sentimentos de pavor a morte e, também, adaptações físicas, psicológicas, familiares, sociais e sentimental. Neste sentido, através dos relatos, identificou-se que não é fácil das mulheres lidarem com o diagnóstico de câncer de mama e nem após a mastectomia, tornando-se um processo de difícil enfrentamento. Afirmação que é reforçada pela fala de outras participantes da pesquisa, como poderemos ver a seguir:

"A palavra: "você tem câncer", machuca. Dói, ouvir que você teve isso porque é algo que remete à doença, pois traz a lembrança de quando eu recebi o resultado que tava com isso. Foi quando meu mundo caiu." [D]

"Quando eu me vi naquela situação, pensei que não tinha jeito, que ia ficar sem meu seio, e que teria que me acostumar, mais até agora ainda não consegui me acostumar [...]." [M]

Diante desta situação, o suporte psicológico a estas mulheres é de extrema importância para auxilia-las no enfrentamento, pois é tido como um importante fator na recuperação de sua saúde. Oliveira MCM, et al., (2013), afirmam que o suporte psicológico, para mulheres que passaram pela mastectomia, bem como pela quadrantectomia, deve ser primordial no pós-operatório, uma vez que as pacientes podem ter um prejuízo na percepção da identidade e, consequentemente, nas suas relações sociais e aceitação da sua autoimagem.

A negação à doença é comum em pacientes oncológicos, principalmente, em mulheres pós mastectomia, pois a dor da multilação reflete em seu dia-dia por terem que enfrentar a sua própria imagem perante as dificuldades da sua própria aceitação, além de enfrentarem outros tipos de problemas, como até mesmo em sua sexualidade, como podemos ver logo abaixo:

“Eu já tinha vergonha porque quando a gente tem filho, já não fica do mesmo jeito, aí então agora eu fiquei com mais vergonha ainda. Eu não tiro a camisa para ter relação sexual, se quiser fazer, vai fazer assim mesmo." [C]

"Sou divorciada, eu me sinto preparada para uma nova relação, só que é difícil e constrangedor de mostrar mais [...]." [G]

A compreensão sobre o seu corpo traz à mulher sentimentos pessimistas pela falta de uma parte de seu corpo, proporcionando, assim, impressão de incompletude, onde haverá sentimentos de decepção, desesperança, timidez e descredito com a própria imagem, negação de sua condição atual e modificações na sua sexualidade (MOURA, et al., 2010).

Pelo seio ser considerado na sociedade como símbolo de beleza cultural e representatividade da identidade, já que faz parte do sexo feminino, tem sua importância no processo de amamentação, assim como na vida sexual, no entanto, após a mastectomia, percebe-se modificações no cotidiano destas mulheres.

Verenhitach BD, et al., (2014) afirmam que ocorrem diversas fases terapêuticas, que abrangem desde a mastectomia, seguido pela quimioterapia e radioterapia e diversas medicações que interferem pontualmente na vida sexual destas mulheres, além da imagem fisica que fica desfigurada com a retirada desta mama.

\section{Mudanças em suas interações sociais...}

Através da mudança de estilo de vida, também surgem mudanças nos relacionamentos sociais e isso é refletido no convívio social em que a mulher esta inserida, pois ocorrem perdas de amizades que podem colaborar para a baixa de sua autoestima, principalmente, pelo fato de não se sentir mais aceita, como vemos na fala de uma participante da pesquisa:

"As pessoas ficam mais distantes da gente. Os amigos que se dizem amigos, porém não são, eles se afastam um pouco da gente, eu me sentia assim, alguns colegas não se afastaram, mas as outras se afastaram de mim, eu não sei se é no tempo que eu bebia e fumava, elas sempre estavam do meu lado, logo depois que eu parei com esses hábitos elas se afastaram de mim [...]." [P] 
Freire MSS, et al., ( 2012) afirmam que o câncer de mama na mulher não modifica, apenas, o seu corpo e sua identidade de ser feminina, mas, também, tem reflexo em suas relações sociais e emocionais que são debilitadas por uma doença que traz, para sí, marcas e discriminações que deverão ser enfrentadas. No meio social, a mama é tida como órgão representativo da mulher com os quais se tem laços culturais e que trazem o padrão do corpo feminino de ser belo. Frente a sociedade, a ausência da mama representa a falta da identidade feminine, gerando, assim, a perda do padrão imposto pela sociedade e colocando a mulher em situações rotineiras que a deixam em posição de receio de mostrar seu próprio corpo:

\section{"Eu não uso biquíni, tenho vergonha de tirar minha blusa assim [...]." [C]}

Problema afirmado por Souza LV, et al., (2016), onde os padrões culturais determinados pela sociedade ocidental moderna fazem com que as mulheres tenham uma maior vulnerabilidade para a depressão, associada às alterações físicas impostas por tratamentos conservadores de remoção cirúrgica. Diante desta mudança, repercute-se significativamente num impacto biopsicossocial.

\section{Fatores de risco que contribuem para o surgimento do câncer de mama}

A neoplasia mamária ainda tem origem desconhecida, entretanto, pode manifestar-se por alguns fatores de risco, dentre eles: menstruação precoce (antes dos 12 anos), menopausa tardia (acima de 55 anos), primeira gestação acima de 30 anos, nunca ter tido filhos, idade, fatores genéticos, ingestão de bebidas alcoólicas, sobrepeso, obesidade, tabagismo (INCA, 2014). Dentre os fatores associados e que foram identificados em nossa pesquisa, os hábitos sociais e os vícios, que algumas entrevistadas têm ou tiveram, puderam repercurtir como um dos fatores de risco para o desenvolvimento do câncer, como veremos abaixo:

"Já fumei, acho que uns 12 anos, bebi bebidas Alcoólicas algumas vezes, pouco tempo também, mas nunca utilizei drogas [...]. "[M]

O histórico familiar de câncer e o aparecimento precoce (menos de 50 anos) pode representar predisposição genética, associada à mutação genética de genes que nos protegem do aparecimento de cânceres (como o BRCA1 e BRCA2) e, quando sofrem mutações, eles perdem sua capacidade protetora, tornando-nos mais susceptíveis ao surgimento de tumors malignos, no entanto, câncer de mama de caráter hereditário representa cerca de 5 a $10 \%$ de todos os casos (ADAMI H et al., 2008).

Neste sentido, um dos fatores de risco com relevância ao desenvolvimento do câncer de mama é a hereditariedade, pois a maioria das entrevistadas relataram casos de câncer na família, como descrito por uma participante:

"Sim, a minha bisavó teve câncer de mama e minha tia, irmã da minha mãe, teve câncer de útero." [N]

O histórico familiar é importantíssimo quando se tem parentes de $1^{\circ}$ grau (mãe ou irmâ) que desenvolveram câncer antes dos 50 anos (SANTOS $\mathrm{J}$ et al., 2014). O risco duplica ou triplica para o desenvolvimento de neoplasias com predisposição genética (OMS, 2015).

Além do fator genético, a ingestão exagerada de alimentos industrializados com auto teor de calorias, gorduras saturadas, ácidos graxos trans, açúcares simples e sódio, juntamente com a redução de consumo de verduras, legumes e frutas, são evidenciados como um estilo alimentar propício ao desenvolvimento do câncer de mama (TORRES DX et al., 2015). Fato este expresso por uma das participantes da pesquisa onde afirmou que sua alimentação não era rica em legumes, verduras ou frutas, mas em outros alimentos não recomendados:

"Antes de ter câncer, eu me alimentava muito mal, comia muitas besteiras e quase nada de salada." [N]

A origem do câncer de mama tem se vários fatores e continua elucida. A relação entre fatores de risco ambientais e genéticos pode inibir ou proporcionar o surgimento de processos carcinogênico. Em nossa década, tem-se dado destaque a padrão alimentares como alimentos industriais como riscos de serem predisponentes ao aparecimento de vários tipos de câncer, como sendo algo possível de intervenção (GEI R et al., 2015). 


\section{CONCLUSÃO}

A presente pesquisa permitiu-nos concluir que as mulheres com baixa autoestima após a mastectomia se mostraram afetadas com este procedimento envolvendo os aspectos físico e emocional em sua identidade feminina, além de nos apresentar suas experiências em um momento tão delicado, despertando a empatia, frente aos obstáculos por elas vivenciados e, também, serviu para influenciar-nos, enquanto profissionais, para um cuidado mais humanizado a estes pacientes.

\section{REFERÊNCIAS}

1. ADAMI H, et al. Textbook of Cancer Epidemiology. 2. ed. New York: Oxford University Press, 2008. Apud Brasil. Ministério da Saúde. Secretaria de Atenção à Saúde. Departamento de Atenção Básica. Controle dos cânceres do colo do útero e da mama. Brasília: Ministério da Saúde; 2013. 122 p. (Cadernos de Atenção Básica; n. 13).

2. AMBRÓSIO DCM, SANTOS MA. Apoio social à mulher mastectomizada: um estudo de revisão. Revista ciência. saúde coletiva 20 (3) março de 2015.

3. CASTRO EK, et al. Percepção da doença, indicadores de ansiedade e depressão em mulheres com câncer. Psic., Saúde \& Doenças, Lisboa, v. 16, n. 3, p. 359-372, dez. 2015.

4. COSTA AMN, et al. Mulheres e a mastectomia: revisão literária. Revistade Atenção à Saúde. v. 13, n. 44. 2015.

5. FREIRE MSS, et al. Assistência de enfermagem à mulher portadora de câncer de mama com base na teoria do relacionamento interpessoal [Dissertação]. Piauí: Universidade Federal do Piauí - UFPI, 2012. 10p.

6. GEI R, et al. Dietary inflammation potential and postmenopausal breast cancer risk in a German case-control study. The Breast, 2015; 24(4): 491-496.

7. GODOY MK, et al. Mastectomia e estética corporal: uma revisão. Salão do Conhecimento, 2016.

8. GOMES NS, et al. Autoestima e qualidade de vida de mulheres submetidas a cirurgia oncológica de mama. Revista Mineira de Enfermagem. v. 19.2. 2015.

9. INCA. Instituto Nacional de Câncer. José Alencar Gomes da Silva. Cartilha câncer é preciso falar disso. fatores de risco ambientais e hormonais (MS)Ministério da saúde 2014.

10. LAGO EA, et al. Sentimento de mulheres mastectomizadas acerca da autoimagem e alterações na vida diária. Ciência \& Saúde. [Internet]. 2015.

11. MOURA FMJSP, et al. Os sentimentos das mulheres pósmastectomizadas. Esc Anna Nery (impr.). 2010.

12. NASCIMENTO KTS, et al. Sentimentos e fontes de apoio emocional de mulheres em pré-operatório de mastectomia em um hospital-escola. Revista de Enfermagem da UERJ. V. 23, n. 1. Rio de Janeiro.

13. NOAL SJ, BERGAMASCHI. Sentimentos experimentados por mulheres que realizaram mastectomia. Anuário Pesquisa e Extensão Unoesc São Miguel do Oeste. V. 2, 2017.

14. OLIVEIRA MCM, et al. Autoestima, depressão e espiritualidade em pacientes submetidas a mastectomia ou quadrantectomia com linfadenectomia axilar. Revista do Médico Residente. V. 15, n. 3. 2013.

15. ORGANIZAÇÃO MUNDIAL DA SAÚDE. Câncer de mama: prevenção e controle. 2015.

16. PRATES ACL, et al. Indicadores de insatisfação relacionados a imagem corporal em pacientes submetidas a mastectomia. Revista Brasileira de Mastologia. V. 24, n. 1. 2014.

17. SALOMON MFB, et al. Câncer de mama no homem. Rev Bras Mastologia. 2015;25(4):141-5.

18. SANTOS J, et al. Panorama do câncer de mama - indicadores para a política de saúde no Brasil. Revista Enfermagem Contemporânea. 2014; 3(1):80-94.

19. SOUZA LV, et al. Qualidade de vida e depressão em mulheres mastectomizadas. Dissertação (graduação em Fisioterapia) - Centro Universitário Tabosa de Almeida. 2016.

20. SOUZA NHA, et al. Câncer de mama em mulheres jovens: um estudo epidemiológico no nordeste brasileiro. Revista Sanare, v. 16, n. 2. 2017.

21. TORRES DX, et al. Associação entre gordura corporal e lipídios dietéticos de pacientes com câncer de mama. Revista Interdisciplinar, 2015; 8(1):1-8.

22. VERENHITACH BD, et al. Câncer de mama e seus efeitos sobre a sexualidade: uma revisão sistemática sobre a abordagem e tratamento. Revista Femina. 2014;42(1):3-10. 